\title{
Instability of Textile Production in Pakistan: Stochastic Frontier Model Approach
}

\author{
INAYATULLAH KHAN \\ PhD scholar, Department of Economics, Gomal University, D. I. Khan - Pakistan. \\ Email: inayat66@gmail.com \\ Prof. Dr. MOHAMMAD AFZAL \\ Department of Economics, Preston University, Islamabad - Pakistan. \\ Email: profafzal@gmail.com
}

\begin{abstract}
Textile industry is the largest industry of Pakistan and like other industries it is facing not only high and escalating cost of electricity and gas but also lack of market access. This study has computed production uncertainty (PU) due to technical inefficiency (TIE) of textile exporting and manufacturing (TEM) firms in Pakistan. We has obtained data from annual reports of 98 companies for the year 2017-18. We has applied stochastic production frontier approach with half normal distribution of ui. PU with confidence bounds had been computed. Inefficiencies (ui/ci) were statistically significant at $5 \%$ level of significance. The mean PU was 0.0045. The computed scores of PU of TEM firms in Pakistan during 2017-18 showed that maximum numbers of firms had their PU score low and close to minimum PU score and very few firms had high PU score and close to maximum PU score.
\end{abstract}

Keywords: Textile Manufacturing Firms, Production Uncertainty, Technical Inefficiency, Confidence Bounds, MLE Technique, Cobb-Douglas Production Function.

\section{Introduction}

Textile industry is the largest industry of Pakistan and like other industries it is facing not only the high and escalating cost of electricity and gas but also lack of market access. This adversely impacts the textile exporters' ability to meet their commitments. The production uncertainty (PU) also influences the ability of the firms to accept orders from abroad. Enterprises must understand and identify sources of PU and respond accordingly to remain competitive with other firms in the textile exports.

Production uncertainty may be due to different factors and sources. Based on production inefficiency, Bera and Sharma (1999), for the first time, introduced the concept of PU due to technical inefficiency (TIE) and presented analytical expression for measuring firm specific PU by stochastic frontier function. The purpose of the paper is to compute PU of textiles exporting and manufacturing (TEM) firms in Pakistan. Empirical research on PU and its effects on the performance of firms had not received much interest from researchers and the literature was limited on this subject matter. Other studies had not addressed the issue in this perspective.

Owners of firms are worried about utilizing their resources optimally to ensure maximum profit as well as high quality of their products so that they could compete successfully with rival firms. The competitiveness of a firm is the ability to compete with the best practiced firm. It is expected that textile manufacturing firms in Pakistan will use their resources of production efficiently and will move towards technologically 
efficient production frontier to reduce production cost in an optimum way and will improve the quality of products to compete with the firms in the domestic and international textile markets.

The textile industry of Pakistan has shown progress due to easily available local raw material and labour force, simple manufacturing process and government's incentives. It has performed well not only in production but also in export over the last six decades. More recently it has been progressing and has increasing foreign demand.

For many countries, particularly, for some developing countries, like Pakistan the trade openness has brought a sea-change in the way their economy works. It has changed the global trade pattern. It has enhanced the competition among textiles and clothing exporters. China's entrance into WTO (World Trade Organization) has increased its exports.

Firms are required to succeed in changing their basic structure to work in new situations. That requires firms to increase their production capacity and to reduce their production cost in an optimum way. The share of manufactured items in exports of developing countries in the world was 20.4 percent in 1992. It had been increased from 29.4 percent in 2000 to 39 percent in 2009. This trend is expected to continue if these countries increase their manufacturing production capacity. Then manufacturing activities will be transferred to developing countries to reduce production costs (UNIDO $\left.{ }^{1} 2011,153\right)$.

The paper has followed the following structure. Section II highlights the significance of Pakistan's textile industry. Section III provides brief review of studies. Section IV concisely discusses the methodology and data. Empirical results are given in section V. Lastly section VI carries the conclusions with future research suggestions. References have been given at the end.

\section{Pakistan Textile Industry}

Pakistan is desperately dependent on cotton textile and clothing for industrial base and exports that account for almost $60 \%$ of the total exports. Textile industry of Pakistan uses local cotton as basic raw material. Pakistan is the fifth largest producer and importer and third largest consumer of cotton in the world (The PACRA (Pakistan Credit Rating Agency Limited) 2020, 7-9).

Textile industry of Pakistan is a labor-intensive industry. The clothing sector provides jobs to unskilled labour. Pakistan is the sixth country in the world regarding population and has the low cost of labor force. According to Hamid, Nabi and Zafar (2014) textile and garments is the largest component of manufacturing sector that accounts for almost $50 \%$ of Pakistan's exports and due to expected future changes in the international trade, this sector has the potential to play an important role in increasing Pakistan's exports. Garments manufacturing is the least energy and capital intensive industrial activity that has attempted to overcome their difficulties.

Table 1: Growth in Capacity

\begin{tabular}{|ccccccc|}
\hline & $\begin{array}{c}\text { Spindles } \\
\text { (Millions) }\end{array}$ & Rotors & $\begin{array}{c}\text { Looms (Mill } \\
\text { Sector) }\end{array}$ & Shuttle less & $\begin{array}{c}\text { Power } \\
\text { looms }\end{array}$ & $\begin{array}{c}\text { Looms } \\
\text { Total }\end{array}$ \\
\hline $2014-15$ & 13.180 & 185,387 & 7,934 & 28,500 & 375,000 & 411,434 \\
$2015-16$ & 13.414 & 187,259 & 8,188 & 28,500 & 375,000 & 411,688 \\
$2016-17$ & 13.414 & 198,801 & 9,084 & 28,500 & 375,000 & 412,584 \\
$2017-18$ & 13.410 & 198,801 & 9,084 & 28,500 & 375,000 & 412,584 \\
\hline
\end{tabular}

Source: GOP, Textile Commissioner Organization $(2017-18,2)$

${ }^{1}$ UNIDO (United Nation Industrial Development Organization) 
Textile exports account for almost $60 \%$ of total exports. As Pakistan has been endowed with cotton production and cheap labor, she has a comparative advantage vis-à-vis her competitors in textile exports. Approximately $\$ 6.4$ billion has been invested in the Textile industry of Pakistan during the 1999-2007 [GOP (Govt. of Pakistan) 2007-08, 39]. The numbers of spindles, rotors and looms has increased significantly since independence but these remained approximately the same for last two years (Table 1).

Table 2: Textile Exports of Pakistan

\begin{tabular}{|ccccccc|}
\hline & $\begin{array}{c}\text { Cotton \& } \\
\text { Cotton } \\
\text { Textiles }\end{array}$ & $\begin{array}{c}\text { Synthetic } \\
\text { Textiles }\end{array}$ & $\begin{array}{c}\text { Wool \& } \\
\text { Woolen } \\
\text { Textiles }\end{array}$ & $\begin{array}{c}\text { Total } \\
\text { Textiles } \\
\text { Exports }\end{array}$ & $\begin{array}{c}\text { Total } \\
\text { Pakistan's } \\
\text { Exports }\end{array}$ & $\begin{array}{c}\% \text { age of } \\
\text { Textiles } \\
\text { Exports }\end{array}$ \\
\hline $2014-15$ & 13139 & 330.743 & 119.448 & 13589 & 23885 & 56.90 \\
$2015-16$ & 12168 & 287.793 & 97.68 & 12553 & 20802 & 60.34 \\
$2016-17$ & 12205 & 187.587 & 78.506 & 12529 & 20478 & 61.35 \\
$2017-18$ & 13220 & 309.681 & 75.852 & 13606 & 23222 & 58.59 \\
\hline
\end{tabular}

Source: GOP $(2018-19,38)$

Textile sector has inherent potential for the longest domestic production chain. It starts from ginning to spinning, knitting/weaving, dyeing and finishing, made ups and garments. At each operational stage, it has in-built high value addition potential. The percentage share of textiles in total exports of Pakistan had been remained vulnerable (Table 2). The yarn and cloth production in Pakistan has increased slightly for last few years as shown in Table 3.

Table 3: Growth in Production

\begin{tabular}{|ccccc|}
\hline & Yarn Production & \multicolumn{3}{c|}{ Cloth Production: (Millions Square Meters) } \\
\cline { 3 - 5 } & (Millions Kgs) & Mill Sector & Non-Mill Sector & Total \\
$2014-15$ & $3,369.7$ & $1,036.9$ & $8,089.6$ & $9,126.5$ \\
$2015-16$ & $3,397.3$ & $1,039.1$ & $8,120.1$ & $9,159.2$ \\
$2016-17$ & $3,428.1$ & $1,043.3$ & $8,126.4$ & $9,169.7$ \\
$2017-18$ & $3,430.1$ & $1,043.7$ & $8,127.2$ & $9,170.9$ \\
\hline
\end{tabular}

Source: GOP, Textile Commissioner Organization $(2017-18,2)$

The textile sector specially the clothing sector has also significance in Pakistan's economy because this is the second largest sector which is suitable for women and provides considerable job opportunities outside the house. The cotton textile industry has played a crucial role in the progress of Pakistan's economy.

\begin{tabular}{|c|c|c|c|c|c|c|}
\hline & $\begin{array}{l}\text { Cotton } \\
\text { Manufacture }\end{array}$ & $\begin{array}{l}\text { Leather \& } \\
\text { Leather } \\
\text { Manufacture }\end{array}$ & Rice & $\begin{array}{l}\text { Sub-Total of } \\
\text { Three Items }\end{array}$ & $\begin{array}{l}\text { Other } \\
\text { Items }\end{array}$ & Total \\
\hline 2014-15 & 54.5 & 4.8 & 8.5 & 67.8 & 32.2 & 100 \\
\hline 2015-16 & 55 & 4.9 & 8.8 & 68.7 & 31.3 & 100 \\
\hline 2016-17 & 59.4 & 4.5 & 7.9 & 71.8 & 28.2 & 100 \\
\hline 2017-18 & 56.9 & 4.6 & 8.8 & 70.3 & 29.7 & 100 \\
\hline
\end{tabular}

Source: GOP $(2018-19,127)$

Exports basket of Pakistan contains few items. The bifurcation of the items in Table 4 shows that export in the few items is the major factor for lower export earnings. The three categories of exports has accounted for 70.3 percent of total exports during 2017-18. 
Table 5: Significance of Textile Industry

\begin{tabular}{|lccc|}
\hline & $2015-16$ & $2016-17$ & $2017-18$ \\
\hline$\%$ in Total exports & 60.34 & 61.35 & 58.59 \\
$\%$ in Manufacturing & 46 & 46 & 46 \\
$\%$ in Industrial employment & 40 & 40 & 40 \\
Machinery Imports ${ }^{\text {b }}$ & 461.51 & 556.83 & 545.11 \\
(US\$ Million) & & & \\
\hline
\end{tabular}

Source: a. GOP (various issues)

b. GOP, Textile Commissioner Organization (2017-18)

Table 5 indicated the significance of textile industry in Pakistan's economy. Textile sector of Pakistan is one of the major contributors to exports as shown in first row of the Table .It has played vital role in earning foreign exchange and jobs in the economy for the last more than six decades. It provides employment to $40 \%$ of industrial labour force. It is expected, textile sector will continue to play a significant role in the growth of Pakistan's economy as there is no other sector that has the same potential to benefit it.

\section{Review of Literature}

Review of stochastic frontier (SF) literature revealed that the researchers had taken much interest in estimating TE and factors which affect the TIE of a firm. But analyzing the behavior of other measures of E $\left(\mathrm{u}_{\mathrm{i}} / \varepsilon_{\mathrm{i}}\right)$ in comparison with observational error had remained neglected in empirical research. Jondrow, Lovel, Materov and Schmidt (1982) suggested E $\left[\mathrm{u}_{\mathrm{i}} / \varepsilon_{\mathrm{i}}\right]$ as a measure of firm specific TIE. Bera and Sharma (1999) introduced the concept of PU due to TIE and presented analytical expression to estimate it by SF function with inefficiency term $\left(\mathrm{u}_{\mathrm{i}}\right)$ distributed as half normal, truncated normal and exponential. They derived the analytical expressions for confidence intervals for inefficiency. They also illustrated their concepts using the model and data set of the U.S. electric utility industry.

Koirala and Koshal (2004) followed the approach of Bera and Sharma (1999) to find firm level PU for carpet industry of Nepal using the CMI (Census of Manufacturing Industries) data for 1992, 1997 separately and also for combined data. Production function was applied to find firm level PU by the standard error of TE. Although they did not give firm level value of PU in their paper but in Table 3 on page 363, they had written 32.46 and 17.56 as the average PU for 1992 and 1997 data respectively. They also found average $\mathrm{PU}=257.13$ for the combined data. These results were ambiguous as TE had range in a $(0,1)$ interval. Therefore, mean, variance and the standard error of it couldnot exceed one. How average PU had so big value, was questionable?

Bandyopadhyay and Das (2006) have also tried to evaluate PU by assuming a SF model whose error components (statistical noise $\mathrm{v}_{\mathrm{i}}$ and inefficiency term $\mathrm{u}_{\mathrm{i}}$ ) are jointly distributed as truncated bivariate normal. They derived the analytical expressions for the firm level $\mathrm{E}\left(\mathrm{u}_{\mathrm{i}} / \varepsilon_{\mathrm{i}}\right)$ and PU and their confidence intervals, but they imposed the condition that the distribution of $\varepsilon_{\mathrm{i}}$ should be negatively skewed.

Duong (2016) examined technical efficiency of Foreign Direct Investment (FDI) firms in the Vietnamese manufacturing sector and used stochastic production frontier model and concluded that the average level of technical efficiency of FDI firms was about $60 \%$ that was higher than that of domestic firms. The study also reported correlation between technical efficiency of FDI firms and other factors.

This brief review of existing literature shows that the researchers have not given much attention to an interesting and significant area of PU. So, this study will add a humble contribution to the literature on firm level production uncertainty. 


\section{Methodology and Data}

We followed Bera and Sharma (1999) approach to measure production uncertainty of TEM firms in Pakistan. We also computed the confidence intervals for inefficiency ui $/ \varepsilon_{\mathrm{i}}$ of each firm and have used the hypothesis tests for the significance of ui $/ \varepsilon_{\mathrm{i}}$. Bera and Sharma (1999) suggested that PU due to TIE at the firm level could be measured empirically by the standard error of the TIE term $u_{i}$ on the given entire compose error term $\varepsilon_{\mathrm{i} \text {.of }}$ the firm. The SF model introduced by Aigner, Lovell and Schmidt (1977) and Meeusen and Broeck (1977) independently is given by the following expression:

$$
\mathrm{OP}_{\mathrm{i}}=\mathrm{f}\left(\mathrm{X}_{\mathrm{i}, \mathrm{b}}\right)+\varepsilon_{\mathrm{i}}
$$

Where "OP${ }_{i}$ " represents output, " $\mathrm{X}_{\mathrm{i}}$ " shows the vector of non-stochastic inputs and " $\varepsilon_{i}$ " denotes the stochastic error term of the ith firm. "f" denotes the production function and "b" represents the vector of parameters to be estimated. For production function, they assume the error term $\varepsilon_{\mathrm{i}}$ as:

$$
\varepsilon_{i}=v_{i}-u_{i},(i=1,2,3 \ldots . N)
$$

The $\mathrm{v}_{\mathrm{i}}$ and the $\mathrm{u}_{\mathrm{i}}$ are independent component of $\varepsilon_{\mathrm{i}}$ and the $\mathrm{v}_{\mathrm{i}}$ is normally distributed random error having zero mean and $\sigma_{\mathrm{v}}{ }^{2}$ variance $\left(\mathrm{v}_{\mathrm{i}} \sim \mathrm{N}\left[0, \sigma_{\mathrm{v}}{ }^{2}\right]\right)$. The $\mathrm{v}_{\mathrm{i}}$ shows effects on production due to external factors which are outside the control of the firm (e.g. climate, natural disasters, luck and measurement error). They have also assumed that the $u_{i}$ is one-sided $\left(u_{i} \geq 0\right)$ and a firm specific which measures deviation from the best practiced frontier due to internal factors. It represents TIE effects which are behavior factors and can be controlled by a firm. It reflects the managerial capability.

Here we have assumed that the $\mathrm{u}_{\mathrm{i}}$ had a half-normal distribution $\left(\mathrm{u}_{\mathrm{i}} \sim \mathrm{N}\left(0, \sigma_{\mathrm{u}}{ }^{2}\right)\right.$.

Bera and Sharma (1999) had defined probability density function (p.d.f) of $u_{i}$ as

$$
k\left(u_{i}\right)=\frac{2}{\sqrt{2} \pi} \frac{1}{\sigma_{u}} \exp \left\{-\frac{u_{i}^{2}}{2 \sigma_{u}^{2}}\right\}, \text { ui }>0
$$

And the p.d.f of $u_{i} / \varepsilon_{i}$ as

$$
\begin{gathered}
f\left(\frac{u_{i}}{\varepsilon \mathrm{i}}\right)=\frac{1}{\left\{1-\emptyset\left(r_{i}\right)\right\}} \frac{1}{\sqrt{2 \pi}} \frac{1}{\sigma^{*}} \exp \left\{-\frac{\left(u_{i}-\mu_{i}^{*}\right)^{2}}{2 \sigma^{*}}\right\}, \mathrm{ui} \geq 0 \\
\text { Here } \quad \mu_{\mathrm{i}}{ }^{*}=-\varepsilon_{\mathrm{i}} \sigma_{\mathrm{u}}{ }^{2} / \sigma^{2}, \quad \sigma_{*}{ }^{2}=\sigma_{\mathrm{u}}{ }^{2} \sigma_{\mathrm{v}}{ }^{2} / \sigma^{2} \\
\sigma^{2}=\sigma_{\mathrm{u}}{ }^{2}+\sigma_{\mathrm{v}}{ }^{2} \quad \text { and } \mathrm{r}_{\mathrm{i}}=-\mu_{\mathrm{i}}{ }^{*} / \sigma^{*}
\end{gathered}
$$

They extended the idea of Jondrow et al. (1982), that the $\mathrm{E}\left(\mathrm{u}_{\mathrm{i}} / \varepsilon_{\mathrm{i}}\right)$ is the expression for TIE and could be derived from equation (a). The values of $\mathrm{E}\left(\mathrm{u}_{\mathrm{i}} / \varepsilon_{\mathrm{i}}\right)$ for each firm could be predicted by following expression.

$$
\mathrm{E}\left[\mathrm{u}_{\mathrm{i}} / \varepsilon_{\mathrm{i}}\right]=\mu_{\mathrm{i}}^{*}+\sigma * \mathrm{~h}\left(\mathrm{r}_{\mathrm{i}}\right)
$$

And $h(\mathrm{ri})=\frac{\Phi(\mathrm{ri})}{1-\phi(\mathrm{ri})}$, where $\Phi($.$) represents the cumulative distribution function (c.d.f) and \phi($. denotes the probability distribution function (p.d.f) of a standard normal random variable.

The conditional variance of the inefficiency term $\mathrm{u}_{\mathrm{i}}$ conditional on the specified whole combine error term $\varepsilon_{\mathrm{i}}$ is $\operatorname{Var}[\mathrm{ui} / \varepsilon \mathrm{i}]$. They defined variance of $\left(\mathrm{u}_{\mathrm{i}} / \varepsilon_{\mathrm{i}}\right)$ as under: 


$$
\operatorname{Var}\left[\mathrm{u}_{\mathrm{i}} / \varepsilon_{\mathrm{i}}\right]=\sigma_{*}^{2}\left\{1+\mathrm{r}_{\mathrm{i}} \mathrm{h}\left(\mathrm{r}_{\mathrm{i}}\right)-\mathrm{h}^{2}\left(\mathrm{r}_{\mathrm{i}}\right)\right\}
$$

For empirical research purpose and conducting hypothesis tests, they have proposed PU due to TIE, as the standard errors of firm level $\mathrm{E}\left(\mathrm{u}_{\mathrm{i}} / \varepsilon_{\mathrm{i}}\right)$ estimates. The values of PU for each firm according to their definition could be estimated by the following equation.

$$
\mathrm{PU}_{\mathrm{i}}=\sqrt{\text { Variance [ui/si] }}=\sqrt{ } \sigma_{*}^{2}\left\{1+\mathrm{r}_{\mathrm{i}} \mathrm{h}\left(\mathrm{r}_{\mathrm{i}}\right)-\mathrm{h}^{2}\left(\mathrm{r}_{\mathrm{i}}\right)\right\}
$$

When a firm has a higher level of PU then there is larger space for improvement in production of that firm.

\section{Confidence Bounds for $\left(\mathrm{u}_{\mathrm{i}} / \varepsilon_{\mathrm{i}}\right)$ and Hypothesis Testing}

From the conditional mean $\mathrm{E}\left(\mathrm{u}_{\mathrm{i}} / \varepsilon_{\mathrm{i}}\right)$ and variance $\operatorname{Var}\left(\mathrm{u}_{\mathrm{i}} / \varepsilon_{\mathrm{i}}\right)$, Bera and Sharma (1999) suggested $(1-\alpha)$ $100 \%$ confidence interval for the inefficiency $\mathrm{u}_{\mathrm{i}} / \varepsilon_{\mathrm{i}}$.

The lower confidence bound for ith firm $\left(\mathrm{LCB}_{\mathrm{i}}\right)$ for inefficiency $\left(\mathrm{u}_{\mathrm{i}} / \varepsilon_{\mathrm{i}}\right)$ was simplified as:

$$
\operatorname{LCB}_{\mathrm{i}}=\mu_{\mathrm{i}}{ }^{*}+\Phi^{-1}\left[\alpha / 2+(1-\alpha / 2) \Phi\left(\mathrm{r}_{\mathrm{i}}\right)\right] \sigma^{*}
$$

And the upper confidence bound $\left(\mathrm{UCB}_{\mathrm{i}}\right)$ for ith firm for inefficiency $\left(\mathrm{u}_{\mathrm{i}} / \varepsilon_{\mathrm{i}}\right)$ was calculated by the formula:

$$
\mathrm{UCB}_{\mathrm{i}}=\mu_{\mathrm{i}}^{*}+\Phi^{-1}\left[1-\alpha / 2\left\{1-\Phi\left(\mathrm{r}_{\mathrm{i}}\right)\right\}\right] \sigma^{*}
$$

To conduct hypotheses tests for the significance of the $\mathrm{E}\left(\mathrm{u}_{\mathrm{i}} / \varepsilon_{\mathrm{i}}\right)$ at firm level, Bera and Sharma (1999) have suggested the procedure for researchers as under:

If the null hypothesis is:

$$
\mathrm{H}_{\mathrm{O}}: \mathrm{E}\left[\mathrm{u}_{\mathrm{i}} / \varepsilon_{\mathrm{i}}\right]=0
$$

And alternative hypothesis for one sided test is:

$$
\text { Ha: } \mathrm{E}\left[\mathrm{u}_{\mathrm{i}} / \varepsilon_{\mathrm{i}}\right]>0
$$

Then one should use $\mathrm{E}\left[\mathrm{u}_{\mathrm{i}} / \varepsilon_{\mathrm{i}}\right] / \sqrt{\operatorname{Var}[\mathrm{ui} / \mathrm{\varepsilon i}]}=\mathrm{E}\left(\mathrm{u}_{\mathrm{i}} / \varepsilon_{\mathrm{i}}\right) /\left(\mathrm{PU}_{\mathrm{i}}\right)$ and compare it for accepting or rejecting the null hypothesis with only the upper critical value defined as:

$$
\begin{aligned}
& \int_{c u}^{\infty} f(w i) \mathrm{d} w \mathrm{i}=\alpha \\
& \text { Here } \quad W i=\frac{\text { ui-E [ui/zi] }}{\sqrt{\operatorname{Var}[u i / \varepsilon i]}}
\end{aligned}
$$

The test for the significance of ith firm inefficiency to accept or reject the null hypothesis was performed by comparing the value $\mathrm{E}\left(\mathrm{u}_{\mathrm{i}} / \varepsilon_{\mathrm{i}}\right) /\left(\mathrm{PU}_{\mathrm{i}}\right)$ with $\alpha=0.05$. 


\section{Data}

Availability of necessary and relevant data of Pakistan's textile manufacturing firms, due to some limitations, is the crux of problem. In this study, we had tried to obtain a consistent dataset. The data used in this study had been collected from the annual reports of 98 TEM firms for the year 2017-18. The names of these firms are available with the author that can be provided on request. Some of the annual reports had been downloaded from Karachi stock exchange and the websites of the companies and the others were copied from Lahore stock exchange personally. The monetary values of all variables used in the model were reported in thousands rupee (Pakistan's currency unit) terms.

We could not find information about labor force employed from all firms' reports. Thus, in the empirical model, we had used all variables in terms of thousands rupees (we had used wages, salaries and other benefits of labor instead of the total number of employees or hours). Battese and Corra (1977); Pitt and Lee (1981); Salim (2006); Singh, Pramatma and Singh (2007); Sasidaran and Shanmugam (2008); Goplan and Shanmugam (2010); Sheikh and Ahmed (2011) had also used cost of labor in their econometric production models. This allows the researcher to control for heterogeneity in labor quality across firms and also avoid inputs heterogeneity. Data of those TEM firms in Pakistan that had exported their products during the year 2017-18 were used.

\section{Empirical Model}

A standard log-linear Cobb-Douglas SF output specification with the half-normal distribution to estimate parameters of different input variables for TEM firms in Pakistan has been assumed as under:

$\ln \mathrm{OPF}_{\mathrm{i}}=\mathrm{b}_{0}+\mathrm{b}_{1} \ln \mathrm{OFA}_{\mathrm{i}}+\mathrm{b}_{2} \ln \mathrm{RM}_{\mathrm{i}}+\mathrm{b}_{3} \ln \mathrm{EC}_{\mathrm{i}}+\mathrm{b}_{4} \ln \mathrm{SW}_{\mathrm{i}}+\mathrm{V}_{\mathrm{i}}+\mathrm{U}_{\mathrm{i}}$

Here, the character "i" on the lower case is a symbol for individual firm $1,2,3, \ldots \ldots, 98$

$\ln =$ natural logarithm

$\mathrm{b}_{0}=$ constant term

$b_{i}=$ Parameter of explanatory variables, subscript i denotes $1,2,3,4$

$\mathrm{OPF}=$ Output of the firm $=$ Net Sale - distribution cost + Change in finished goods + Change in work in process - Purchase for resale during the year

$\mathrm{OFA}=$ Net value of Operating Fixed Assets of the firm during the year

$\mathrm{RM}=$ Total amount spent on "Raw \& packing material + Stores and spares + Chemical \& dyes" consumed + Processing /stitching /weaving /knitting charges etc. during the year

$\mathrm{EC}=$ Total amount spent on Fuel and power and water charges during the year

$\mathrm{SW}=$ Total amount of Salaries, wages, and other benefits of workers during the year

$\mathrm{V}=$ Random error

$\mathrm{U}=\mathrm{TIE}$

The SF output model given in equation 6 was estimated by Maximum Likelihood estimation (MLE) technique. The half-normal distribution of $u_{i}$ had been selected. As for truncated normal distribution of $u_{i}$, the data was not converged, i.e. the software STATA had not shown the results.

The likelihood function had been parameterized in terms of $\sigma^{2}=\sigma_{u}{ }^{2}+\sigma_{v}{ }^{2}$ and $\lambda=\left(\sigma_{u} / \sigma_{v}\right) \geq 0$ and estimation had been shown in Table 6.

\section{Production Uncertainty Analysis}

The estimated parameters of the variables along with standard errors, $\mathrm{z}$ - scores, p - values and $95 \%$ confidence intervals for technical efficiency are presented in Table 6. 
Table 6: The Results of Estimated Model (6)

Dependent Variable is OPF (output of a firm) $\quad$ Number of observation $=98$

Log likelihood function $=68.8642 \quad$ Number of iteration $=04$

\begin{tabular}{|ccccccc|}
\hline Variables & $\begin{array}{c}\text { Estimated } \\
\text { parameters }\end{array}$ & Standard error & z-scores & $\begin{array}{c}\mathrm{p}- \\
\text { values }\end{array}$ & \multicolumn{2}{c|}{$95 \%$ CI } \\
\hline Intercept & 0.878 & 0.1879 & 4.8 & 0.000 & 0.4947 & 1.2987 \\
OFA & 0.048 & 0.0378 & 1.59 & 0.102 & -0.0123 & 0.0778 \\
RM & 0.6998 & 0.0308 & 24.9 & 0.000 & 0.6748 & 0.7498 \\
EC & 0.0971 & 0.0250 & 3.94 & 0.004 & 0.0477 & 0.1701 \\
SW & 0.1623 & 0.0291 & 4.81 & 0.001 & 0.08817 & 0.2213 \\
$\sigma_{v}$ & 0.0895 & 0.0169 & - & - & 0.0599 & 0.13228 \\
$\sigma_{\mathrm{u}}$ & 0.1429 & 0.0349 & - & - & 0.0910 & 0.2299 \\
$\sigma^{2}$ & 0.0279 & 0.0080 & - & - & 0.0134 & 0.0389 \\
$\lambda$ & 1.5984 & 0.0498 & - & - & 1.4937 & 1.6982 \\
\hline
\end{tabular}

Source: Author computation

L-R test of $\sigma_{u}=0 ; \quad \chi^{2}(01)=2.58, \quad$ Prob $>=\chi^{2}=0.054$

The software did not show $\mathrm{z}$ - scores and $\mathrm{p}$ - values of the error terms, $\sigma$ and $\lambda$. Therefore, these values were not shown in Table 6. The likelihood ratio test of $u_{i}$ presented the value of 2.58 (significant at 0.05 ). The results of estimated model in Table 6 showed that all variables had expected sign and $\lambda>0$ i.e. 1.5984, therefore our model was fitted well. All estimated parameters of dependent variables had expected positive sign and these were significant at $1 \%$ level except OFA (operating fixed asset) which was significant at 10 $\%$ level.

Here the value of $\lambda>0$ i.e. $\lambda \cong 1.60$ and was statistically different from zero. This indicated that the use of $\mathrm{SF}$ in regression was acceptable. Therefore, the model used to compute $\mathrm{E}\left(\mathrm{u}_{\mathrm{i}} / \varepsilon_{\mathrm{i}}\right)$ and PU of TEM firms in Pakistan for 2017-18 and the specification of distributional assumption were appropriate. Further RM (cost of Raw material) had maximum elasticity of production i.e. 0.6998 than other inputs. SW (Salaries, wages, and other benefits) had the second maximum elasticity of production i.e. 0.162.

To compute PU of TEM firms of Pakistan, first the value of $\hat{\varepsilon_{\mathrm{i}}}$ had been computed as the difference of observed $\mathrm{OP}_{\mathrm{i}}$ and fitted $\mathrm{OP}_{\mathrm{i}}$ of the estimated model (6). Then, the value of $\mu_{\mathrm{i}}{ }^{*}, \sigma_{*}{ }^{2}$ and $\mathrm{r}_{\mathrm{i}}$ had been obtained by using the value of $\sigma_{v}, \sigma_{u}$, and $\sigma^{2}$ from the table and computed $\varepsilon_{\mathrm{i}}$ of each firm.

The $\Phi\left(r_{i}\right)$ had been calculated by using the Microsoft Excel and $\phi\left(r_{i}\right)$ had been computed with the help of $\mathrm{Z}$ table - normal distribution calculator. Putting these values in equations (2), the values of PU of individual firms had been obtained. The $\mathrm{LCB}_{\mathrm{i}}$ and $\mathrm{UCB}_{\mathrm{i}}$ for PU of each firm had also been computed by using equations (3) and (4).

Tests had been performed for the significance of i-th firms' inefficiency to accept or reject the null hypothesis by comparing the value $\mathrm{E}\left(\mathrm{u}_{\mathrm{i}} / \varepsilon_{\mathrm{i}}\right) /\left(\mathrm{PU}_{\mathrm{i}}\right)$ with $\alpha$ calculated by equation 5 . If the value of $\mathrm{E}\left(\mathrm{u}_{\mathrm{i}} / \varepsilon_{\mathrm{i}}\right)$ / $\left(\mathrm{PU}_{\mathrm{i}}\right)$ of $\mathrm{i}$-th firm was greater than 0.05 , then the null hypothesis was rejected and the value of $\mathrm{i}$-th firm's inefficiency was statistically significant. 
Table 7: Estimated error $\varepsilon_{\mathrm{i}}, \mathrm{E}\left(\mathrm{u}_{\mathrm{i}} / \varepsilon_{\mathrm{i}}\right), \mathrm{PU} \mathrm{i}, 95 \%$ CI for $\mathrm{u}_{\mathrm{i}} / \varepsilon_{\mathrm{i}}$ Table 7 (a)

\begin{tabular}{|c|c|c|c|c|c|c|c|}
\hline Grade & Firm No & $\varepsilon_{\mathrm{i}}$ & $\mathrm{E}\left(\mathrm{u}_{\mathrm{i}} / \varepsilon_{\mathrm{i}}\right)$ & $\mathrm{PU}_{\mathrm{i}}$ & $\mathrm{LCB}_{\mathrm{i}}$ & $\mathrm{UCB}_{\mathrm{i}}$ & $\begin{array}{l}\mathrm{E}\left(\mathrm{u}_{\mathrm{i}} / \varepsilon_{\mathrm{i}}\right) / \\
\mathrm{PU}_{\mathrm{i}}\end{array}$ \\
\hline 1 & 95 & 0.1155 & 0.0198 & 0.0037 & 0.0012 & 0.1225 & 5.3514 \\
\hline 2 & 44 & 0.1137 & 0.0201 & 0.0037 & 0.0012 & 0.1231 & 5.4324 \\
\hline 3 & 63 & 0.108 & 0.0208 & 0.0037 & 0.0012 & 0.125 & 5.6216 \\
\hline 4 & 75 & 0.0962 & 0.0222 & 0.0038 & 0.0013 & 0.1292 & 5.8421 \\
\hline 5 & 57 & 0.0946 & 0.0223 & 0.0038 & 0.0013 & 0.1298 & 5.8684 \\
\hline 6 & 5 & 0.0864 & 0.0232 & 0.0038 & 0.0014 & 0.1328 & 6.1053 \\
\hline 7 & 7 & 0.0847 & 0.0233 & 0.0038 & 0.0014 & 0.1335 & 6.1316 \\
\hline 8 & 90 & -0.0521 & 0.0666 & 0.0038 & 0.0037 & 0.1983 & 17.5263 \\
\hline 9 & 50 & -0.0526 & 0.0669 & 0.0038 & 0.0037 & 0.1986 & 17.6053 \\
\hline 10 & 81 & -0.0541 & 0.0677 & 0.0038 & 0.0037 & 0.1995 & 17.8158 \\
\hline 11 & 23 & -0.056 & 0.0687 & 0.0038 & 0.0038 & 0.2006 & 18.0789 \\
\hline 12 & 66 & -0.0626 & 0.0722 & 0.0038 & 0.004 & 0.2044 & 19.0000 \\
\hline 13 & 15 & -0.0631 & 0.0724 & 0.0038 & 0.0041 & 0.2047 & 19.0526 \\
\hline 14 & 91 & -0.0645 & 0.0731 & 0.0038 & 0.0041 & 0.2055 & 19.2368 \\
\hline 15 & 270 & -0.0662 & 0.074 & 0.0038 & 0.0042 & 0.2065 & 19.4737 \\
\hline 16 & 35 & -0.0665 & 0.0742 & 0.0038 & 0.0042 & 0.2067 & 19.5263 \\
\hline 17 & 2 & -0.0666 & 0.0742 & 0.0038 & 0.0042 & 0.2067 & 19.5263 \\
\hline 18 & 53 & -0.0701 & 0.076 & 0.0038 & 0.0044 & 0.2088 & 20.0000 \\
\hline 19 & 39 & -0.0719 & 0.077 & 0.0038 & 0.0044 & 0.2099 & 20.2632 \\
\hline 20 & 98 & -0.0732 & 0.0776 & 0.0038 & 0.0045 & 0.2106 & 20.4211 \\
\hline 21 & 25 & 0.0652 & 0.0254 & 0.0039 & 0.0016 & 0.1411 & 6.5128 \\
\hline 22 & 56 & -0.0377 & 0.059 & 0.0039 & 0.0032 & 0.1902 & 15.1282 \\
\hline 23 & 67 & -0.0758 & 0.079 & 0.0039 & 0.0046 & 0.2122 & 20.2564 \\
\hline 24 & 24 & -0.0775 & 0.0799 & 0.0039 & 0.0047 & 0.2132 & 20.4872 \\
\hline 25 & 38 & -0.0775 & 0.0799 & 0.0039 & 0.0047 & 0.2132 & 20.4872 \\
\hline 26 & 71 & -0.0788 & 0.0805 & 0.0039 & 0.0048 & 0.214 & 20.6410 \\
\hline 27 & 11 & -0.0789 & 0.0806 & 0.0039 & 0.0048 & 0.2141 & 20.6667 \\
\hline 28 & 62 & -0.0802 & 0.0813 & 0.0039 & 0.0048 & 0.2149 & 20.8462 \\
\hline
\end{tabular}


Table 7 (b)

\begin{tabular}{|c|c|c|c|c|c|c|c|}
\hline Grade & Firms No & $\varepsilon_{\mathrm{i}}$ & $\mathrm{E}\left(\mathrm{u}_{\mathrm{i}} / \varepsilon_{\mathrm{i}}\right)$ & $\mathrm{PU}_{\mathrm{i}}$ & $\mathrm{LCB}_{\mathrm{i}}$ & $\mathrm{UCB}_{\mathrm{i}}$ & $\begin{array}{l}\mathrm{E}\left(\mathrm{u}_{\mathrm{i}} / \varepsilon_{\mathrm{i}}\right) / \\
\mathrm{PU}_{\mathrm{i}}\end{array}$ \\
\hline 29 & 59 & -0.0846 & 0.0835 & 0.0039 & 0.005 & 0.2176 & 21.4103 \\
\hline 30 & 93 & -0.0871 & 0.0848 & 0.0039 & 0.0052 & 0.2191 & 21.7436 \\
\hline 31 & 42 & 0.0579 & 0.0263 & 0.004 & 0.0016 & 0.1441 & 6.5750 \\
\hline 32 & 74 & 0.0555 & 0.0266 & 0.004 & 0.0016 & 0.145 & 6.6500 \\
\hline 33 & 34 & -0.0283 & 0.0539 & 0.004 & 0.003 & 0.1851 & 13.4750 \\
\hline 34 & 70 & -0.0296 & 0.0546 & 0.004 & 0.003 & 0.1858 & 13.6500 \\
\hline 35 & 54 & -0.0309 & 0.0553 & 0.004 & 0.003 & 0.1865 & 13.8250 \\
\hline 36 & 80 & -0.0937 & 0.0882 & 0.004 & 0.0056 & 0.2231 & 22.0500 \\
\hline 37 & 8 & -0.0951 & 0.0889 & 0.004 & 0.0056 & 0.224 & 22.2250 \\
\hline 38 & 65 & -0.0964 & 0.0896 & 0.004 & 0.0057 & 0.2248 & 22.4000 \\
\hline 39 & 92 & -0.0975 & 0.0901 & 0.004 & 0.0058 & 0.2255 & 22.5250 \\
\hline 40 & 82 & -0.0991 & 0.091 & 0.004 & 0.0059 & 0.2265 & 22.7500 \\
\hline 41 & 69 & -0.1039 & 0.0935 & 0.004 & 0.0062 & 0.2295 & 23.3750 \\
\hline 42 & 72 & -0.104 & 0.0935 & 0.004 & 0.0062 & 0.2296 & 23.3750 \\
\hline 43 & 10 & 0.0387 & 0.0292 & 0.0041 & 0.0018 & 0.1523 & 7.1220 \\
\hline 44 & 13 & -0.0163 & 0.0473 & 0.0041 & 0.0027 & 0.1788 & 11.5366 \\
\hline 45 & 37 & -0.0175 & 0.048 & 0.0041 & 0.0027 & 0.1794 & 11.7073 \\
\hline 46 & 86 & -0.0191 & 0.0488 & 0.0041 & 0.0028 & 0.1802 & 11.9024 \\
\hline 47 & 30 & -0.1055 & 0.0943 & 0.0041 & 0.0063 & 0.2305 & 23.0000 \\
\hline 48 & 83 & -0.1076 & 0.0954 & 0.0041 & 0.0065 & 0.2319 & 23.2683 \\
\hline 49 & 1 & -0.1077 & 0.0954 & 0.0041 & 0.0065 & 0.232 & 23.2683 \\
\hline 50 & 47 & -0.1088 & 0.096 & 0.0041 & 0.0066 & 0.2327 & 23.4146 \\
\hline 51 & 6 & -0.0097 & 0.0436 & 0.0042 & 0.0026 & 0.1754 & 10.3810 \\
\hline 52 & 4 & -0.119 & 0.1013 & 0.0042 & 0.0074 & 0.2392 & 24.1190 \\
\hline 53 & 52 & -0.12 & 0.1019 & 0.0042 & 0.0075 & 0.2398 & 24.2619 \\
\hline 54 & 55 & -0.1221 & 0.103 & 0.0042 & 0.0077 & 0.2412 & 24.5238 \\
\hline 55 & 29 & -0.1238 & 0.1039 & 0.0042 & 0.0078 & 0.2423 & 24.7381 \\
\hline 56 & 33 & 0.1554 & 0.012 & 0.0043 & 0.001 & 0.11 & 2.7907 \\
\hline 57 & 94 & 0.0095 & 0.0354 & 0.0043 & 0.0022 & 0.1658 & 8.2326 \\
\hline
\end{tabular}


Table 7 (c)

\begin{tabular}{|c|c|c|c|c|c|c|c|}
\hline Grade & Firms No & $\varepsilon_{\mathrm{i}}$ & $\mathrm{E}\left(\mathrm{u}_{\mathrm{i}} / \varepsilon_{\mathrm{i}}\right)$ & $\mathrm{PU}_{\mathrm{i}}$ & $\mathrm{LCB}_{\mathrm{i}}$ & $\mathrm{UCB}_{\mathrm{i}}$ & $\begin{array}{l}\mathrm{E}\left(\mathrm{u}_{\mathrm{i}} / \varepsilon_{\mathrm{i}}\right) / \\
\mathrm{PU}_{\mathrm{i}}\end{array}$ \\
\hline 58 & 96 & 0.0006 & 0.0378 & 0.0043 & 0.0024 & 0.1701 & 8.7907 \\
\hline 59 & 61 & -0.1307 & 0.1076 & 0.0043 & 0.0085 & 0.2468 & 25.0233 \\
\hline 60 & 22 & -0.133 & 0.1089 & 0.0044 & 0.0088 & 0.2484 & 24.7500 \\
\hline 61 & 16 & -0.1342 & 0.1095 & 0.0044 & 0.0089 & 0.2491 & 24.8864 \\
\hline 62 & 28 & -0.1353 & 0.1101 & 0.0044 & 0.009 & 0.2499 & 25.0227 \\
\hline 63 & 89 & -0.1453 & 0.1156 & 0.0045 & 0.0103 & 0.2565 & 25.6889 \\
\hline 64 & 31 & -0.1521 & 0.1194 & 0.0046 & 0.0112 & 0.261 & 25.9565 \\
\hline 65 & 78 & -0.1537 & 0.1203 & 0.0046 & 0.0114 & 0.2621 & 26.1522 \\
\hline 66 & 26 & -0.1554 & 0.1213 & 0.0046 & 0.0117 & 0.2633 & 26.3696 \\
\hline 67 & 45 & -0.1579 & 0.1227 & 0.0047 & 0.0121 & 0.265 & 26.1064 \\
\hline 68 & 32 & -0.1595 & 0.1236 & 0.0047 & 0.0123 & 0.266 & 26.2979 \\
\hline 69 & 40 & -0.1598 & 0.1238 & 0.0047 & 0.0124 & 0.2663 & 26.3404 \\
\hline 70 & 51 & -0.1652 & 0.1269 & 0.0048 & 0.0133 & 0.2699 & 26.4375 \\
\hline 71 & 97 & -0.1711 & 0.1304 & 0.0048 & 0.0144 & 0.2739 & 27.1667 \\
\hline 72 & 68 & -0.1734 & 0.1318 & 0.0049 & 0.0149 & 0.2756 & 26.8980 \\
\hline 73 & 84 & -0.176 & 0.1333 & 0.0049 & 0.0154 & 0.2773 & 27.2041 \\
\hline 74 & 77 & -0.1851 & 0.1388 & 0.005 & 0.0174 & 0.2836 & 27.7600 \\
\hline 75 & 87 & -0.2022 & 0.1496 & 0.0052 & 0.022 & 0.2955 & 28.7692 \\
\hline 76 & 20 & -0.2029 & 0.15 & 0.0052 & 0.0222 & 0.296 & 28.8462 \\
\hline 77 & 18 & -0.2034 & 0.1503 & 0.0052 & 0.0224 & 0.2964 & 28.9038 \\
\hline 78 & 14 & -0.2035 & 0.1504 & 0.0052 & 0.0224 & 0.2964 & 28.9231 \\
\hline 79 & 76 & -0.2085 & 0.1536 & 0.0052 & 0.0239 & 0.2999 & 29.5385 \\
\hline 80 & 17 & -0.2112 & 0.1553 & 0.0053 & 0.0248 & 0.3018 & 29.3019 \\
\hline 81 & 4909 & -0.2153 & 0.158 & 0.0053 & 0.0262 & 0.3047 & 29.8113 \\
\hline 82 & 73 & -0.2171 & 0.1592 & 0.0053 & 0.0269 & 0.306 & 30.0377 \\
\hline 83 & 19 & -0.2179 & 0.1597 & 0.0053 & 0.0272 & 0.3065 & 30.1321 \\
\hline 84 & 12 & -0.2357 & 0.1715 & 0.0055 & 0.0343 & 0.3191 & 31.1818 \\
\hline 85 & 9 & -0.239 & 0.1738 & 0.0055 & 0.0357 & 0.3215 & 31.6000 \\
\hline 86 & 41 & -0.2471 & 0.1793 & 0.0055 & 0.0395 & 0.3272 & 32.6000 \\
\hline 87 & 43 & -0.2523 & 0.1829 & 0.0056 & 0.0421 & 0.3309 & 32.6607 \\
\hline 88 & 46 & -0.276 & 0.1993 & 0.0056 & 0.0549 & 0.3478 & 35.5893 \\
\hline 89 & 3 & -0.2799 & 0.2021 & 0.0057 & 0.0572 & 0.3507 & 35.4561 \\
\hline 90 & 48 & -0.2806 & 0.2025 & 0.0057 & 0.0576 & 0.3511 & 35.5263 \\
\hline 91 & 85 & -0.2883 & 0.208 & 0.0057 & 0.0623 & 0.3566 & 36.4912 \\
\hline 92 & 21 & -0.3382 & 0.2435 & 0.0058 & 0.0952 & 0.3925 & 41.9828 \\
\hline 93 & 64 & -0.3415 & 0.2459 & 0.0058 & 0.0975 & 0.3949 & 42.3966 \\
\hline 94 & 58 & -0.3479 & 0.2505 & 0.0058 & 0.1019 & 0.3994 & 43.1897 \\
\hline 95 & 60 & -0.3529 & 0.2541 & 0.0058 & 0.1055 & 0.4031 & 43.8103 \\
\hline 96 & 79 & -0.3702 & 0.2665 & 0.0058 & 0.1177 & 0.4155 & 45.9483 \\
\hline 97 & 88 & -0.4065 & 0.2926 & 0.0058 & 0.1436 & 0.4417 & 50.4483 \\
\hline \multirow[t]{2}{*}{98} & 36 & -0.5708 & 0.4109 & 0.0058 & 0.2618 & 0.5599 & 70.8448 \\
\hline & Average & & 0.1080 & 0.0045 & & & \\
\hline
\end{tabular}

\section{Source: Author computation (from Table 6)}

From the computed $\mathrm{LCB}_{\mathrm{i}}$ and $\mathrm{UCB}_{\mathrm{i}}$ values and the tests for the null hypothesis performed for $\mathrm{E}\left(\mathrm{u}_{\mathrm{i}} / \varepsilon_{\mathrm{i}}\right)$ and PU of each individual firms, it had been found that the values of inefficiencies for each TEM firm were statistically significant at $5 \%$ level of significance, as all the values of $\mathrm{E}\left(\mathrm{u}_{\mathrm{i}} / \varepsilon_{\mathrm{i}}\right) / \mathrm{PU}_{\mathrm{i}}$ were greater than 0.05 (Table 7). 


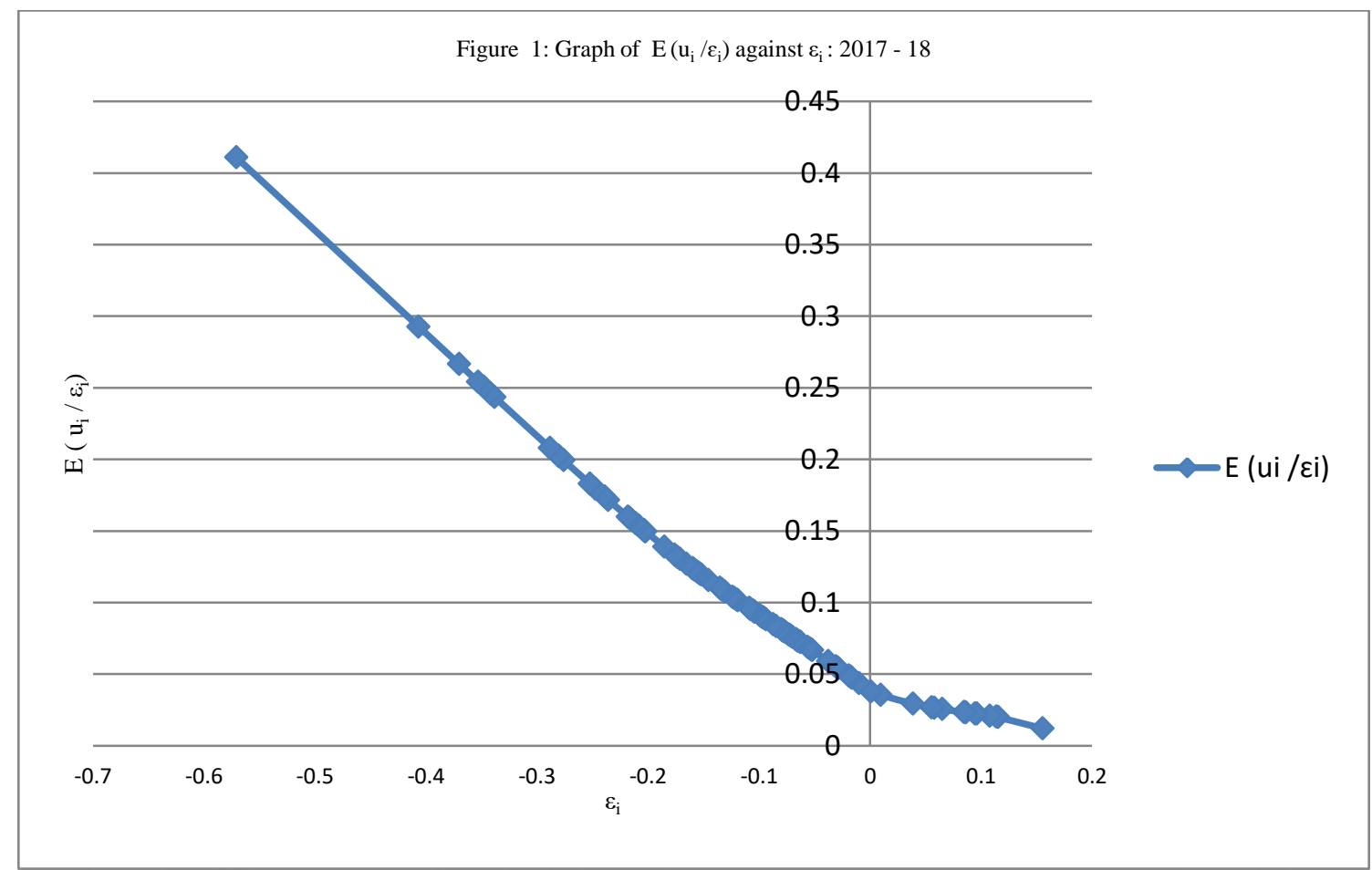

Source: Author computation (from Table 7)

Inefficiencies $\mathrm{E}\left(\mathrm{u}_{\mathrm{i}} / \varepsilon_{\mathrm{i}}\right)$ of TEM firms in Pakistan for 2017-18 were between 0.012 and 0.4109 and the mean $\mathrm{E}\left(\mathrm{u}_{\mathrm{i}} / \varepsilon_{\mathrm{i}}\right)$ was equal to 0.1080 . Therefore, the firms of Pakistan were not achieving 100 percent of production potential during the year. The PU in Pakistan's TEM firms for 2017-18 was between 0.0037 and 0.0058 and the mean PU was equal to 0.0045 .

Similarly, the relationship with estimated $\mathrm{PU}_{\mathrm{i}}$ and estimated $\boldsymbol{\varepsilon}_{\mathbf{i}}$ of TEM firms is not monotonically decreasing, when ${ }^{\wedge} \boldsymbol{\varepsilon}_{\mathbf{i}}$ had the value near to zero or greater than zero. When $\mathrm{E}\left(\mathrm{u}_{\mathrm{i}} / \varepsilon_{\mathrm{i}}\right)$ was the largest i.e. 0.4109 then PU was the largest i.e. 0.0058. But when E $\left(\mathrm{u}_{\mathrm{i}} / \varepsilon_{\mathrm{i}}\right)$ was smallest then PU had not the smallest value (Table 7).

The graph of estimated E $\left(\mathrm{u}_{\mathrm{i}} / \varepsilon_{\mathrm{i}}\right)$ of TEM firms in Pakistan against estimated $\boldsymbol{\varepsilon}_{\mathrm{i}}$ is shown in Figure 1. It is obvious that when $\boldsymbol{\varepsilon}_{\mathbf{i}}$ has negative value then the relationship with $\mathrm{E}\left(\mathrm{u}_{\mathrm{i}} / \varepsilon_{\mathrm{i}}\right)$ and ${ }^{{ }^{2}} \boldsymbol{\varepsilon}_{\mathrm{i}}$ is monotonically decreasing but when $\hat{\boldsymbol{\varepsilon}}_{\mathbf{i}}$ has positive value then the relationship does not hold good for 2017-18 data set.

The scores of $\mathrm{E}\left(\mathrm{u}_{\mathrm{i}} / \varepsilon_{\mathrm{i}}\right)$ of Pakistan's TEM firms for the year 2017-18 were depicted in the Figure 2 with confidence intervals. The upper line shows the $\mathrm{UCB}_{\mathrm{i}}$ for $\mathrm{E}\left(\mathrm{u}_{\mathrm{i}} / \varepsilon_{\mathrm{i}}\right)$ of individual firms, middle line shows $\mathrm{E}$ $\left(\mathrm{u}_{\mathrm{i}} / \varepsilon_{\mathrm{i}}\right)$ of the same individual firms while lower line shows the $\mathrm{LCB}_{\mathrm{i}}$ of the same individual firms. It is obvious from Figure 2 that when the level of $\mathrm{E}\left(\mathrm{u}_{\mathrm{i}} / \varepsilon_{\mathrm{i}}\right)$ is small then the width of $\mathrm{CI}$ is small and when the level of $\mathrm{E}\left(\mathrm{u}_{\mathrm{i}} / \varepsilon_{\mathrm{i}}\right)$ is high then the width of CI is large. 


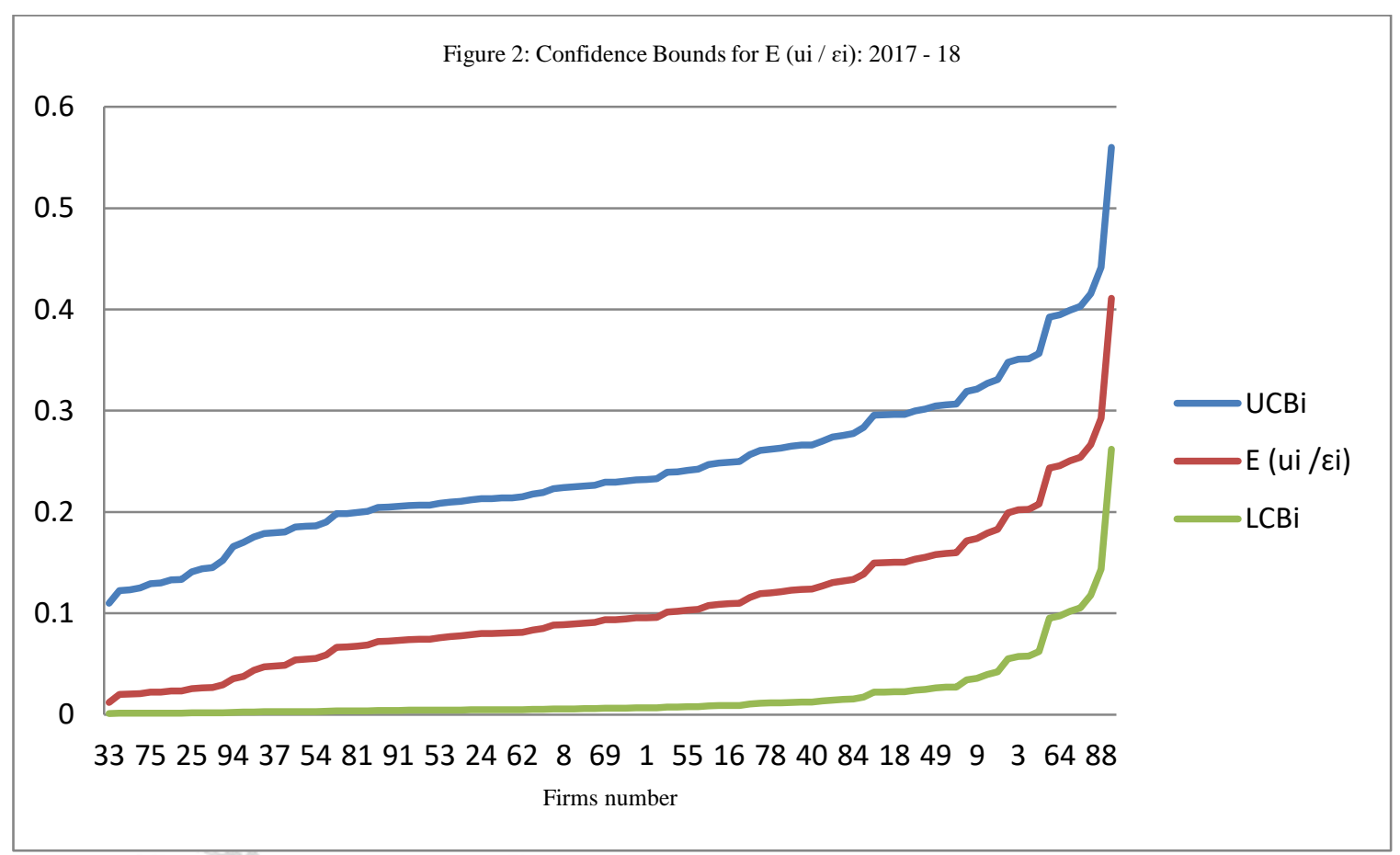

\section{Conclusions}

This study had estimated risk or variation in firm specific production (due to TIE) of TEM firms in Pakistan for year 2017-18. Bera and Sharma (1999) called it as firm specific production uncertainty (PU). The estimated PU scores remained on average between 0.0037 and 0.0058 . And on average mean PU is equal to 0.0045. The computed scores of PU of TEM firms in Pakistan during 2017-18 showed that maximum number of firms had their PU score low and close to minimum PU score and very few firms had high PU score and close to maximum PU score. According to Bera and Sharma (1999), a firm having the lowest PU score is most efficient one. This study had revealed that maximum numbers of firms were working on efficient level and had a little instability and the lowest variation (due to TIE) in their production.

\section{Suggestions for Future Research}

Different tracks for future research are proposed as;

First, this study had estimated PU due to TIE by Bera and Sharma (1999) approach. They assumed that the relationship between estimated $\mathrm{E}\left(\mathrm{u}_{\mathrm{i}} / \varepsilon_{\mathrm{i}}\right)$ score of a firm and estimated error term $\varepsilon_{\mathrm{i}}$ of SF output function and the relationship between estimated PUi and $\varepsilon_{\mathrm{i}}$ are monotonically decreasing, but in this study, it had been revealed that when the residual $\varepsilon_{\mathrm{i}}$ has positive value then, these relationships does not hold good. Econometricians in future may make efforts to resolve these problems for better results.

Second, this study had used labour cost instead of numbers of labourers or hours of labour in the SF output function. If, one of these is available in future, that should be used for better analysis of output function. Third, in this study, data of Public limited companies had been used. Private companies and small and medium enterprises may also be included in future research to analyze the entire trend of PU of TEM firms in Pakistan, if the relevant data of these companies is available. 


\section{References}

Aigner, D. J., Lovell, C. A. \& Schmidt, P. (1977). Formulation and estimation of stochastic frontier production function models. Journal of Econometrics, 6 (1), 21-37.

Bandyopadhyay, D. \& Das, A. (2006). On measures of technical inefficiency and production uncertainty in stochastic frontier production model with correlated error components. Journal of Productivity Analysis, 26:165-180.

Battese, G.E. \& Corra, G.S. (1977). Estimation of a production frontier model: With application to the pastoral zone of eastern Australia. Australian Journal of Agricultural Economics, 21(3), 169-179.

Bera, A. K. \& Sharma, S. C. (1999). Estimating production uncertainty in stochastic frontier production function model. Journal of Productivity Analysis, 12, 187-210.

Cobb, C. W. \& Douglas, P. H. (1928). A theory of production. American Economic Review 18(1), 139 165.

Duong Hoang (2016). Technical efficiency of FDI firms in the Vietnamese manufacturing

sector. Review of economic perspectives, 16(3), 205-203.

Government of Pakistan. Pakistan Economic Survey (various issues). Islamabad, economic advisors wing, finance division.

Government of Pakistan (2017-18). Textile Commissioner Organization. Karachi, ministry of commerce \& textile, textile division.

Goplan, S., \&Shanmugam, K.R. (2010). The Multi-Fibre agreement phase-out: Efficiency Implications of Textile Firms in India. Trade and Development Review, 3(1), 59-75.

Greene, W. H. (1990). A Gamma-distributed stochastic frontier Model. Journal of Econometrics, 46, 141 163.

Hamid Naveed, Ijaz Nabi, \& Rafia Zafar (2014). The textiles and garments sector: Moving up the value chain. The Lahore Journal of Economics, 19, 283-306.

Jondrow, J., Lovell, C. A. K., Materov, I. \& Schmidt, P. (1982): On the estimation of technical inefficiency in the stochastic frontier production function model. Journal of Econometrics 19, 233-238.

Koirala, G. \& Koshal R. K. (2004). Effects of production uncertainty on carpet exporting firms in Nepal: A Note. Indian Journal of Economics \& Business, 3(2), 355- 372.

Meeusen, W. \& Broeck J. V. (1977). Efficiency estimation from Cobb-Douglas production functions with composed errors. International Economic Review, 18 (2), 435- 444.

Pitt, M. M., \& Lee, L-F (1981). The measurement and sources of technical inefficiency in the Indonesian weaving industry. Journal of Development Economics, 9 (1), 43-64.

Salim, R. A. (2006). Measuring productive efficiency incorporating firms' heterogeneity: An empirical analysis. Journal of Economic Development, 31(1).

Sasidaran G., \& Shanmugam, K. R. (2008). Impact of trade liberalization on the efficiency of textile firms in India. ISAS (Institute of South Asian Studies). National University of Singapore, Working Paper No. 52.

Sheikh, S. A. \& Ahmed, S. (2011). Impact of trade liberalization and domestic economic reforms on technical efficiency of agro-based industries in Pakistan; International Journal of Business and Social Science, 2(23).

Singh, N.P., Pramatma, Singh, \& Singh, R.P. (2007). Research note, sugar industry in uttar pradesh: efficiency still holds the key. Agricultural Economics Research Review, 20, 157-170.

The PACRA (Pakistan Credit Rating Agency Limited) (2020). Towels sector study, retrieved from: https://www.pacra.com.pk/pages/research/research.php

UNIDO (United Nations Industrial Development Organization) (2011). Industrial development report 2011. Industrial energy efficiency for sustainable wealth creation, captures environmental, economic and social dividends, UNIDO ID No.: 442.

$\mathrm{Z}$ table - Normal distribution calculator compatible with iPhone and iPad. Retrieved from http://davidmlane.com/normal.html. 